\title{
Transanal total mesorectal excision of giant villous tumor of the lower rectum with McKittrick-Wheelock syndrome: a case report of a novel surgical approach
}

\author{
Masahiko Fukase ${ }^{1 *}$, Hiroshi Oshio ${ }^{1}$, Sho Murai ${ }^{1}$, Tomomi Kawana', Yusuke Saito ${ }^{1}$, Emiko Kono ${ }^{1}$, Yukiko Oshima ${ }^{1}$, \\ Gen Yunome', Shin Teshima ${ }^{1}$ and Masaaki Ito ${ }^{2}$
}

\begin{abstract}
Background: McKittrick-Wheelock syndrome (MKWS) is caused by a villous tumor of the rectosigmoid colon with hypersecretion of mucus containing electrolytes. Complete resection of the tumor is needed to cure this disease. Transanal total mesorectal excision (TaTME) is currently a promising treatment for lower rectal tumor because of the reliability of its resection margin especially in bulky tumor. We present this first case report of a TaTME for MKWS with a lower rectal tumor.

Case presentation: An 81-year-old woman was admitted to our hospital with diarrhea and acute renal failure. Computed tomography and magnetic resonance imaging examinations revealed an 80-mm-sized enhanced tumor located in her lower rectum without lymph node swelling and distant metastasis. A giant villous tumor secreting mucus was seen in the lower rectum to the anal canal during colonoscopy. The result of tumor biopsy was adenocarcinoma. To preserve the anal function and ensure distal margin, we chose TaTME for curative resection. After improving the electrolyte imbalance, TaTME was performed successfully and R0 resection was achieved. There was no sign of recurrence or electrolyte depletion for 1 year after the surgery.
\end{abstract}

Conclusion: TaTME could be a promising surgical approach for giant villous tumor with MKWS in the lower rectum.

Keywords: Transanal total mesorectal excision, Villous tumor, McKittrick-Wheelock syndrome, Lower rectal cancer, Total mesorectal incision

\section{Introduction}

McKittrick-Wheelock syndrome (MKWS) was first reported as a rare syndrome characterized by dehydration, electrolyte depletion, and renal failure due to secretory diarrhea from villous tumor of the rectosigmoid colon [1]. This tumor not only causes systemic disease, but also has a risk of malignancy due to its size. The definitive treatment is partial colectomy followed by fluid and electrolyte replacement. An endoscopic approach is a limited option because of its circumference, malignancy,

\footnotetext{
* Correspondence: hukase@surg.med.tohoku.ac.jp

'Department of Surgery, Sendai Medical Center, 2-11-12 Miyagino,

Miyagino-ku, Sendai, Miyagi-ken 983-8520, Japan

Full list of author information is available at the end of the article
}

and location [2-4]. Especially in the case of tumors located in the lower rectum, we cannot avoid choosing abdominal-peritoneal resection, which reduces the patients' quality of life drastically. The technique is sometimes too invasive compared with the risk of malignancy.

Transanal total mesorectal excision (TaTME) is a newly prevalent surgical technique for middle and lower rectal cancer. TaTME has the advantage of obtaining TME and quality of life through visualization of the distal part of the surgical plane especially in case of bulky tumor [5, 6]. Here, we present a first case report of a female patient with MKWS successfully treated by TaTME. 

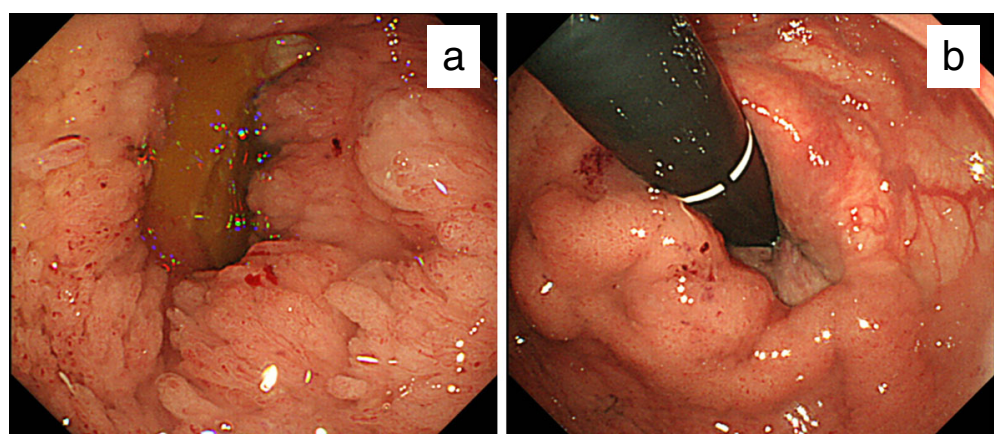

Fig. 1 Colon fiber findings. a A giant villous tumor with rich secretion of mucus was found in the lower rectum. $\mathbf{b}$ The tumor located from the anal canal to $10 \mathrm{~cm}$ on the oral side

\section{Case presentation}

An 81-year-old woman was admitted to our hospital suffering from general fatigue and severe diarrhea, which contained a lot of mucus. On physical examination, she did not have abdominal pain with normal vital sign. Laboratory data showed acute renal failure (creatinine, $3.07 \mathrm{mg} / \mathrm{dL}$; normal range, 0.47 to $0.79 \mathrm{mg} / \mathrm{dL}$ ) with hyponatremia (sodium, $109 \mathrm{mEq} / \mathrm{L}$; normal range, 139 to $146 \mathrm{mEq} / \mathrm{L}$ ), hypokalemia (potassium, $3.6 \mathrm{mEq} / \mathrm{L}$; normal range, 3.7 to $4.8 \mathrm{mEq} / \mathrm{L}$ ), and hypochloremia (chloride, $66 \mathrm{mEq} / \mathrm{L}$; normal range, 101 to $109 \mathrm{mEq} / \mathrm{L}$ ). However, the collected mucus contained a high concentration of electrolytes (sodium, $159 \mathrm{mEq} / \mathrm{L}$; potassium, $14.1 \mathrm{mEq} / \mathrm{L}$; chloride, $140 \mathrm{mEq} / \mathrm{L}$ ). Elevation of the tumor markers carcinoembryonic antigen and carbohydrate antigen 19-9 was not detected. Digital rectal examination revealed huge circumferential mass of the rectum from $4 \mathrm{~cm}$ from anal verge. So we performed a colonoscopy because electrolyte depletion from mucus was considered as a cause of renal dehydration. The lower rectum was occupied by a giant villous tumor located from Hermann's line to $10 \mathrm{~cm}$ on the oral side. The tumor with rich secretion of mucus encompassed the full circumference of the rectum (Fig. 1a, b). Multiple tumor biopsy showed well-differentiated adenocarcinoma cells in some lesion of the tumor. An enhanced mass, $8 \mathrm{~cm}$ in diameter located in the lower rectum without lymph node and distant metastases, was found in a computed tomography (CT) scan (Fig. 2a). The CT colonography showed that the tumor was located in the lower rectum with extending into the anal canal (Fig. 2b). Magnetic resonance imaging showed no sign of infiltration of the vagina and anal sphincter (Fig. 3a, b).

The patient was diagnosed with a villous adenocarcinoma with MKWS because of the typical findings for the villous tumor, such as electrolyte and body fluid depletion with secretory diarrhea. After intensive fluid therapy, tumor resection was required. Transanal endoscopic microsurgery and endoscopic mucosal dissection were excluded because of its circumference and extension. Considering the patient's quality of life and tumor location up to Hermann's line, we chose TaTME as a radical treatment.

We performed TaTME with one team and anal approach first as described below. First, a Lone Star Retractor (Lone Star Medical Products, Houston, TX, USA) was inserted under general anesthesia in the lithotomy position. We used the GelPOINT Path Transanal Access Platform (Applied Medical, Rancho Santa
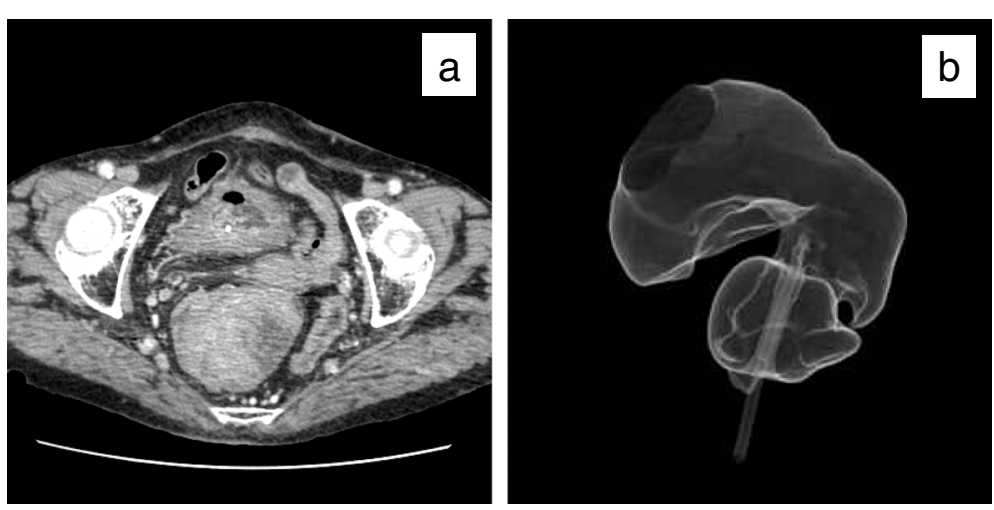

Fig. 2 Computed tomography findings. a Enhanced tumor was found in the lower rectum without lymph node metastasis. b The computed tomography colonography showed that the tumor extended into anal canal 

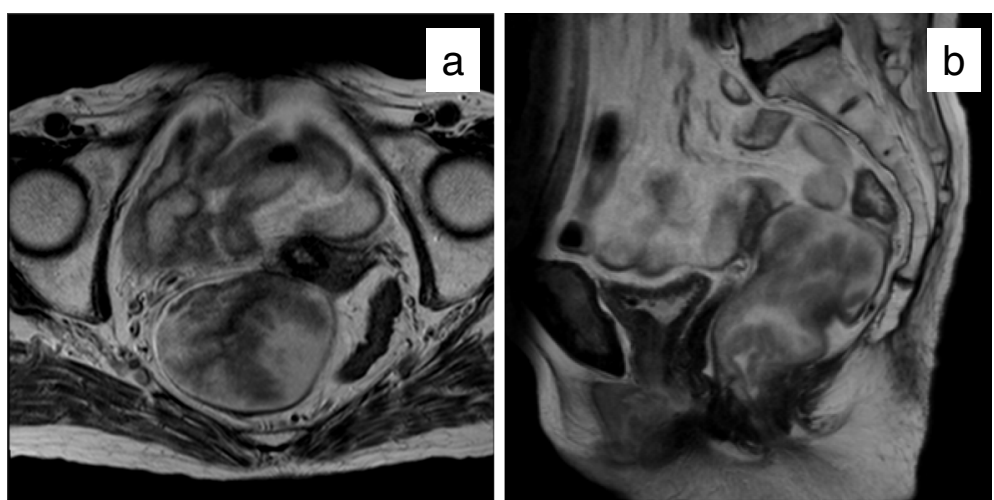

Fig. 3 Magnetic resonance imaging findings. a Axial. b Sagittal. There was no sign of invasion up to the vagina and anal sphincter

Margarita, CA, USA) and AirSeal (ConMed, Utica, NY, USA) as an insufflation system to obtain a stable pneumorectum with smoke evacuation. We pushed the tumor away with gauze because the collapsed giant tumor and a huge amount of mucus interrupted the laparoscopic view. The tumor was located on a hemorrhoid $4 \mathrm{~cm}$ distant from the anal verge (Fig. 4a). At first, circumferential mucosectomy was performed with a 5-mm distal margin from the tumor because its malignancy potential was not as high (Fig. 4b). Then, the lumen of the rectum was closed with a purse-string suture to prevent cancer cell dissemination and mucus leakage. Endopelvic fascia was identified after intersphincteric resection of the muscle. After dissection of the hiatal ligament, the TME plane was revealed in transanal approach (Fig. 4c).
The abdominal cavity was opened at the level of the peritoneal reflection (Fig. 4d). Thus, we inserted five ports and transferred to a traditional laparoscopic TME technique. The inferior mesenteric artery and vein were highly ligated after full mobilization of the left and sigmoid colon with connection to TME plane. A small laparotomy at the umbilical port site was required for extraction of the specimen because the tumor was too bulky. We pulled the stump of the oral colon out anally and performed hand-sewn coloanal anastomosis. Additionally, we constructed a diverting loop ileostomy on the right lower port site. The operative time was 281 min, and the blood loss was $50 \mathrm{~mL}$.

On gross examination, the tumor was a $13.5-\mathrm{cm}$ papillary tumor. The distal margin was more than $5 \mathrm{~mm}$

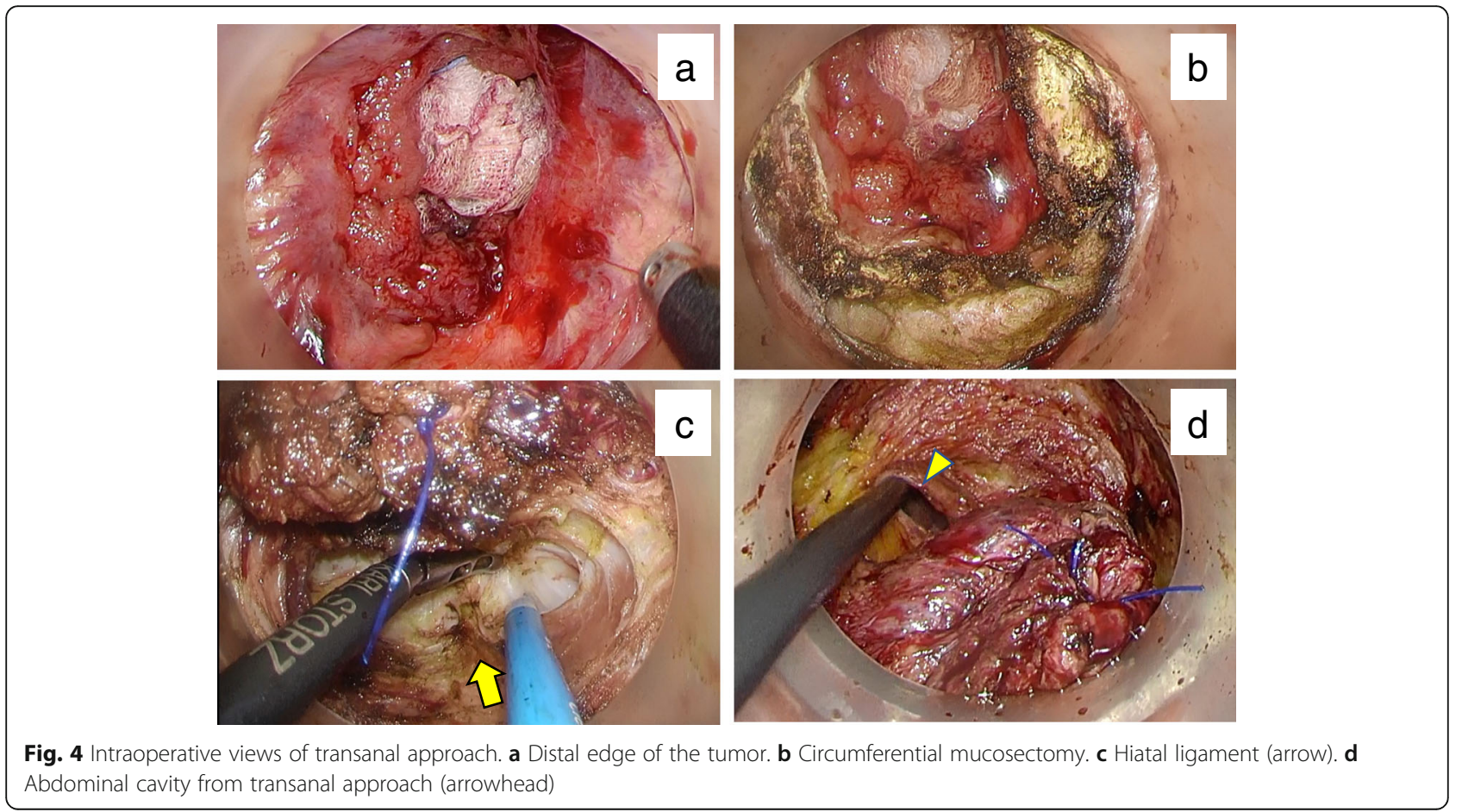


away from the tumor (Fig. 5a). The histological findings showed an intramucosal adenocarcinoma in the tubulovillous adenoma located in the lower rectum without regional lymph node metastasis (Fig. 5b, c). The cancer classification was Tis, N0, M0, stage 0 in Union for International Cancer Control 8th edition. The patient was discharged 14 days after surgery in good general conditions with no postoperative complications, including anastomotic trouble. There was no evidence of recurrence, and we closed the covering ileostomy 5 months after surgery. She had good defecation function and remained well at 12 months after the first surgery. Adjuvant chemotherapy and radiotherapy were not performed, and the patient recovered full activities of daily living.

\section{Discussion}

The MKWS shows hyponatremia, hypokalemia, and hypochloremia because of the loss of a high amount of mucus in the patient's diarrhea. Its triad was chronic mucus diarrhea, renal function impairment with hydroelectrolyte imbalance, and giant rectosigmoid tumor.
The distal location of the tumor prevents reabsorption of abnormally secreted electrolyte in normal colonic mucosa. This is a rare disease, which occurs only in $0.27-2.4 \%$ of villous adenomas representing 3-6\% of colonic tumors [2, 7-9]. The size of tumors with MKWS is usually over $3-4 \mathrm{~cm}$ in diameter. According to a review of 64 reported cases of MKWS, the maximum diameter was $4-26 \mathrm{~cm}$ (mean, $13.9 \mathrm{~cm}$ ). Giant tumors often contain high-grade dysplasia, and $72.4 \%$ of tumors with MKWS were diagnosed as carcinoma $[2,10]$.

The primary treatment is fluid therapy for renal failure before curative therapy. Some conservative therapies were reported in addition to invasive therapies including surgery. Nonsteroidal anti-inflammatory agents, such as cyclooxygenase- 2 inhibitor, contribute to improve severe dehydration and renal failure through reduction of the stool output $[11,12]$. Endocavity irradiation was tried in 19 patients with villous adenoma, which resulted in $32 \%$ recurrence [13]. However, mortality from untreated syndrome was reported in 100\% [14]. Therefore, removal of the tumor is the only radical treatment for this syndrome.
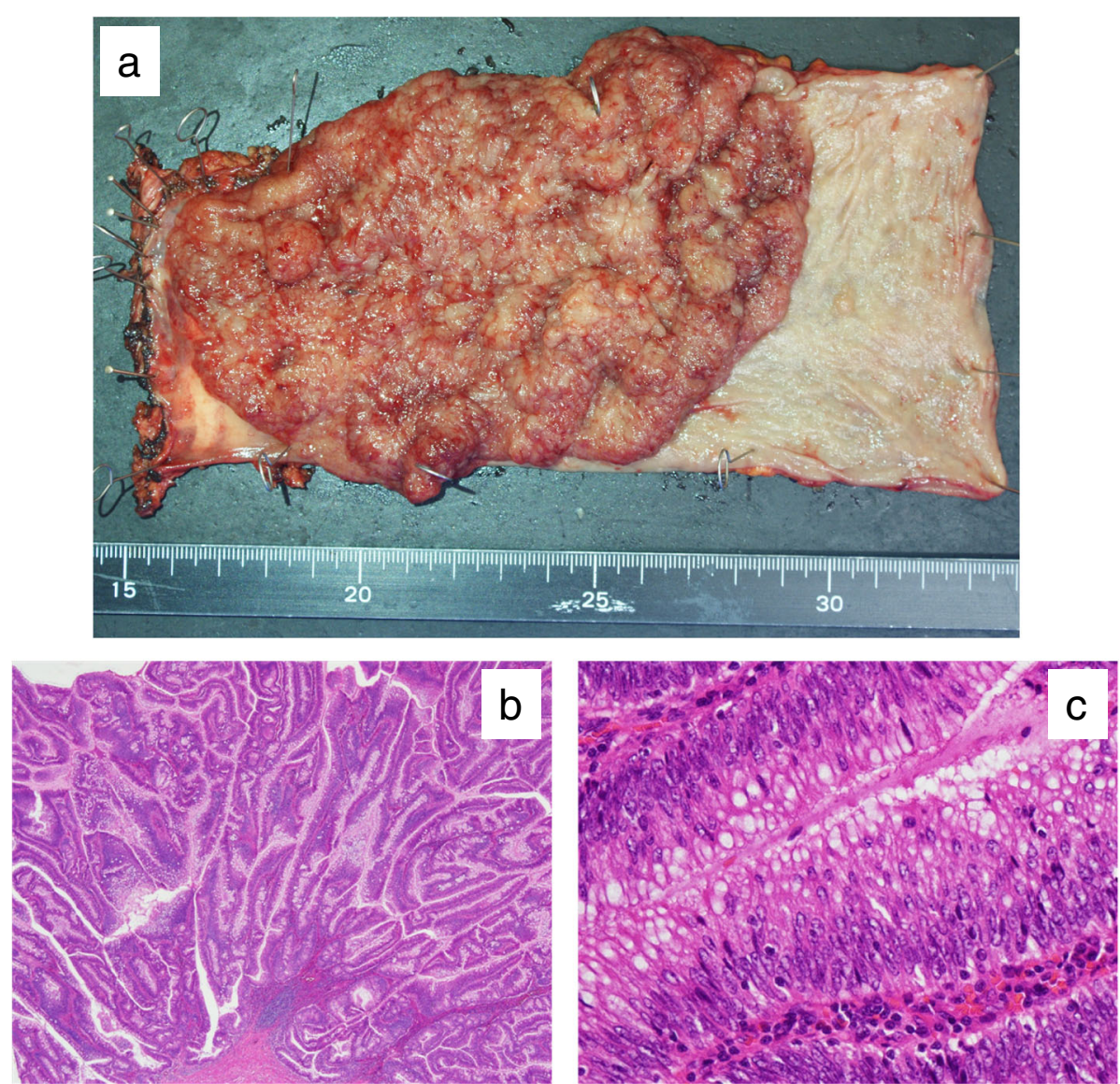

Fig. 5 Surgical specimen and microscopic findings. a A villous tumor at gross examination. b Hematoxylin-eosin stain $(\times 20)$ revealed papillary tumor. c Differentiated adenocarcinoma in tubulovillous adenoma was detected in some lesion $(\times 200)$ 
Table 1 Patients with McKittrick-Wheelock syndrome treated with laparoscopic low anterior resection and proctosigmoidectomy

\begin{tabular}{|c|c|c|c|c|c|c|c|}
\hline Author & Year & Age, sex & Tumor size $(\mathrm{cm})$ & Circumference (\%) & Distance from anal verge & Procedure & Pathology \\
\hline Dagan and Reissman [8] & 2010 & $52, F$ & 31 & 100 & On the dentate line & LPS+TM+DLI & TVA, HGD \\
\hline Podesta et al. [19] & 2014 & $72, F$ & 15 & 100 & On the dentate line & LAR & VA, HGD \\
\hline Choi et al. [20] & 2012 & $59, \mathrm{M}$ & 25 & 100 & $7 \mathrm{~cm}$ & LAR & TVA \\
\hline \multirow[t]{3}{*}{ Targarona et al. [21] } & 2008 & $63, \mathrm{~F}$ & 18 & ND & $<1 \mathrm{~cm}$ & LAR & VA, HGD \\
\hline & & $69, \mathrm{~F}$ & 16 & & $1 \mathrm{~cm}$ & IPS & VA \\
\hline & & $69, F$ & 7 & & $10 \mathrm{~cm}$ & LAR & VA, HGD \\
\hline
\end{tabular}

$\overline{D L I}$ diverting loop ileostomy, HGD high-grade dysplasia, IPS intersphincteric proctosigmoidectomy, LAR laparoscopic low anterior resection, ND not described, $T M$ transanal mucosectomy, TVA tubulovillous adenoma, VA villous adenoma

Among the less-invasive treatments, transanal minimally invasive surgery and transanal endoscopic microsurgery were performed. These were challenging and difficult procedures in giant tumor even in experienced hand. Rectal stricture treated with multiple times dilation was reported as postoperative complication in case of 16-cm villous tumor with MKWS [15, 16]. As endoscopic approach, endoscopic submucosal dissection was reported, even in tumors over $20 \mathrm{~cm}$ in size. However, it always resulted in piecemeal resection because the tumor often covered $100 \%$ of the circumference [17, 18]. Most importantly, these less invasive therapies without TME are not radical therapy for the cases of $\mathrm{T} 1$ adenocarcinomas.

According to previous reports, laparoscopic lower anterior resection and proctosigmoidectomy are the most frequently applied transabdominal surgical procedures for MKWS [8, 15, 19-21]. The summary of these previous reports is shown in Table 1 . The procedures could lead to severe complication such as anastomotic leakage, urinary dysfunction, and surgical site infection $[15,19-24]$. Especially in the case of tumors located in the lower rectum, we cannot avoid choosing abdominalperitoneal resection, which reduces the patient's quality of life dramatically $[10,25]$. The technique is sometimes too invasive; thus, we focused on TaTME as a lessinvasive anal-preserving surgery.

TaTME is a relatively new surgical approach for rectal tumors, which was introduced by Lacy and Adelsdorfer [26]. TaTME can make up for the shortcomings of laparoscopic TME using a transanal laparoscopic platform based on the concept of bottom to top approach. The clinical benefits of TaTME have been reported, such as longer resection margin, low circumferential margin positive rates, less morbidity, and more sphincter-saving rectal resections. Fernández-Hevia et al. reported TaTME had shorter operative time, less readmission, and $1.1 \mathrm{~cm}$ longer distal margin compared to laparoscopic TME [27-29]. The technique has advantages in the cases of narrow pelvis, bulky tumors, and fatty mesorectum. There were some reports of large rectal tumor such as leiomyosarcoma and gastrointestinal stromal tumors occupying the pelvis removed successfully with this approach $[6,30,31]$.

In our case, we discuss the surgical approach to this tumor from the perspectives of curability and quality of life. It is very difficult to accomplish lower anterior resection of the rectum because the huge tumor spread to the anal canal and disturb the laparoscopic view. Abdominal perineal resection would be too invasive for this elderly patient because of her Tis or T1 tumor, although the surgical margin would certainly be obtained. Thus, we chose TaTME as a radical anal-preserving surgery. Purse-string suture could completely prevent flow of plentiful mucus into laparoscopic view. As planned, negative surgical margin was obtained without any complication. This is a first report of a patient of MKWS successfully treated with TaTME.

\section{Conclusion}

Complete resection in this case of giant villous tumor with MKWS was successfully achieved by TaTME without loss of anal function. TaTME could be a promising surgical approach for a villous tumor with MKWS in the lower rectum.

\section{Abbreviations}

$C T$ : Computed tomography; MKWS: McKittrick-Wheelock syndrome; TaTME: Transanal total mesorectal excision

\section{Acknowledgements}

Not applicable

\section{Authors' contributions}

MF wrote the first draft of the manuscript. $\mathrm{HO}$ was the surgeon and physician in charge of this patient. SM, TK, YS, EK, YO, GY, and ST participated in the design of this case. $\mathrm{Ml}$ assisted during the operation and approved of the final manuscript. All authors read and approved the final manuscript.

\section{Funding}

The authors declare that no funding was received for this study.

Availability of data and materials

The dataset supporting the conclusions of this article is included in the article.

Ethics approval and consent to participate Not applicable. 


\section{Consent for publication}

Informed consent was obtained from the patient.

\section{Competing interests}

The authors declare that they have no competing interests.

\section{Author details}

'Department of Surgery, Sendai Medical Center, 2-11-12 Miyagino, Miyagino-ku, Sendai, Miyagi-ken 983-8520, Japan. ${ }^{2}$ Department of Colorectal Surgery, National Cancer Center Hospital East, 6-5-1 Kashiwanoha, Kashiwa-shi, Chiba-ken 277-8577, Japan.

Received: 6 August 2019 Accepted: 10 October 2019

Published online: 06 November 2019

\section{References}

1. McKittrick LS, Wheelock FC. Carcinoma of the colon. 1954. Dis Colon Rectum. 1997:40(12):1494-5 discussion 5-6.

2. Kure K, Kawai M, Ishiyama S, Kamiyama H, Tomiki Y, Sakamoto K, et al. Complete endoscopic submucosal dissection of a giant rectal villous adenocarcinoma with electrolyte depletion syndrome. Case Rep Gastroenterol. 2015:9(2):126-31.

3. Mois El, Graur F, Sechel R, Al-Hajjar N. McKittrick-Wheelock syndrome: a rare case report of acute renal failure. Clujul Med (1957). 2016:89(2):301-3.

4. O'Brien MJ, Winawer SJ, Zauber AG, Gottlieb LS, Sternberg SS, Diaz B, et al. The National Polyp Study. Patient and polyp characteristics associated with high-grade dysplasia in colorectal adenomas. Gastroenterology. 1990:98(2):371-9.

5. Veltcamp Helbach M, Koedam TWA, Knol JJ, Velthuis S, Bonjer HJ, Tuynman $J B$, et al. Quality of life after rectal cancer surgery: differences between laparoscopic and transanal total mesorectal excision. Surgical endoscopy. 2019;33(1):79-87.

6. Adamina M, Buchs NC, Penna M, Hompes R. St. Gallen consensus on safe implementation of transanal total mesorectal excision. Surg Endosc. 2018; 32(3):1091-103.

7. Ikematsu H, Matsuda T, Emura F, Saito Y, Uraoka T, Fu Kl, et al. Efficacy of capillary pattern type IIIA/IIB by magnifying narrow band imaging for estimating depth of invasion of early colorectal neoplasms. BMC Gastroenterol. 2010;10:33.

8. Dagan A, Reissman P. Giant secretory villous adenoma of the rectum and sigmoid presenting as McKittrick-Wheelock syndrome. Int J Color Dis. 2010; 25(7):909-10.

9. Murature Stordiau GE, Suarez Alecha J, Zazpe Ripa C, Lera Tricas JM. Acute renal failure and profund hypokalemia caused by a villous adenoma in the rectum: McKittrick - Wheelock syndrome. Rev Esp Enferm Dig. 2009:101(1):78-9.

10. Popescu A, Orban-Schiopu AM, Becheanu G, Diculescu M. McKittrickWheelock syndrome - a rare cause of acute renal failure. Rom J Gastroenterol. 2005;14(1):63-6.

11. Smelt AH, Meinders AE, Hoekman K, Noort WA, Keirse MJ. Secretory diarrhea in villous adenoma of rectum: effect of treatment with somatostatin and indomethacin. Prostaglandins. 1992;43(6):567-72.

12. Steven $K$, Lange $P$, Bukhave $K$, Rask-Madsen J. Prostaglandin E2-mediated secretory diarrhea in villous adenoma of rectum: effect of treatment with indomethacin. Gastroenterology. 1981;80(6):1562-6.

13. Kovalic JJ. Endocavitary irradiation for rectal cancer and villous adenomas. Int J Radiat Oncol Biol Phys. 1988;14(2):261-4

14. Emrich J, Niemeyer $C$. The secreting villous adenoma as a rare cause of acute renal failure. Med Klin (Munich, Germany: 1983). 2002:97(10):619-23.

15. van der Pool AEM, de Graaf EJR, Vermaas M, Barendse RM, Doornebosch PG. McKittrick Wheelock syndrome treated by transanal minimally invasive surgery: a single-center experience and review of the literature. J Laparoendosc Adv Surg Tech Part A. 2018;28(2):204-8.

16. Barendse RM, van den Brandt S, Dekker E, Fockens P. McKittrick-Wheelock syndrome. Ned Tijdschr Geneeskd. 2013;157(3):A5567.

17. Ohara Y, Toyonaga T, Watanabe D, Hoshi N, Adachi S, Yoshizaki T, et al. Electrolyte depletion syndrome (McKittrick-Wheelock syndrome) successfully treated by endoscopic submucosal dissection. Clin J Gastroenterol. 2015; 8(5):280-4.

18. Abe S, Sakamoto T, Takamaru H, Yamada M, Nakajima T, Matsuda T, et al. Stenosis rates after endoscopic submucosal dissection of large rectal tumors involving greater than three quarters of the luminal circumference. Surg Endosc. 2016:30(12):5459-64.

19. Podesta MA, Cucchiari D, Merizzoli E, Elmore U, Angelini C, Badalamenti S. McKittrick-Wheelock syndrome: a rare cause of acute renal failure and hypokalemia not to be overlooked. Ren Fail. 2014;36(5):811-3.

20. Choi WH, Ryuk J, Kim HJ, Park SY, Park JS, Kim JG, et al. A case of giant rectal villous tumor with severe fluid-electrolyte imbalance treated by laparoscopic low anterior resection. J Korean Surg Soc. 2012;82(5):325-9.

21. Targarona EM, Hernandez PM, Balague C, Martinez C, Hernandez J, Pulido D, et al. McKittrick-Wheelock syndrome treated by laparoscopy: report of 3 cases. Surg Laparosc Endosc Percutan Tech. 2008;18(5):536-8.

22. Sanchez Garcia S, Villarejo Campos P, Manzanares Campillo Mdel C, Gil Rendo A, Munoz Atienza V, Garcia Santos EP, et al. Hypersecretory villous adenoma as the primary cause of an intestinal intussusception and McKittrick-Wheelock syndrome. Canadian journal of gastroenterology = Journal canadien de gastroenterologie. 2013;27(11):621-2.

23. Raphael MJ, CM MD, Detsky AS. McKittrick-Wheelock syndrome. CMAJ. 2015; 187(9):676-8.

24. Khalife M, Eloubeidi MA, Hosn MA. McKittrick-Wheelock syndrome presenting with dermatomyositis and rectal prolapsed. Clin Exp Gastroenterol. 2013;6:85-9.

25. Learney RM, Ziprin P, Swift PA, Faiz OD. Acute renal failure in association with community-acquired clostridium difficile infection and McKittrickWheelock syndrome. Case Rep Gastroenterol. 2011:5(2):438-44.

26. Lacy AM, Adelsdorfer C. Totally transrectal endoscopic total mesorectal excision (TME). Colorectal Dis. 2011;13(Suppl 7):43-6.

27. Deijen CL, Velthuis S, Tsai A, Mavroveli S, de Lange-de Klerk ES, Sietses C, et al. COLOR III: a multicentre randomised clinical trial comparing transanal TME versus laparoscopic TME for mid and low rectal cancer. Surg Endosc. 2016;30(8):3210-5.

28. Fernandez-Hevia M, Delgado S, Castells A, Tasende M, Momblan D, Diaz de Gobbo G, et al. Transanal total mesorectal excision in rectal cancer: shortterm outcomes in comparison with laparoscopic surgery. Ann Surg. 2015; 261(2):221-7.

29. Velthuis S, Nieuwenhuis DH, Ruijter TE, Cuesta MA, Bonjer HJ, Sietses C. Transanal versus traditional laparoscopic total mesorectal excision for rectal carcinoma. Surg Endosc. 2014:28(12):3494-9.

30. Hoshino N, Hida K, Kawada K, Sakurai T, Sakai Y. Transanal total mesorectal excision for a large leiomyosarcoma at the lower rectum: a case report and literature review. Surg Case Rep. 2017;3(1):13.

31. Wachter $N$, Worns MA, Dos Santos DP, Lang H, Huber T, Kneist W. Transanal minimally invasive surgery (TAMIS) approach for large juxta-anal gastrointestinal stromal tumour. J Minim Access Surg. 2016;12(3):289-91.

\section{Publisher's Note}

Springer Nature remains neutral with regard to jurisdictional claims in published maps and institutional affiliations.

\section{Submit your manuscript to a SpringerOpen ${ }^{\circ}$ journal and benefit from}

- Convenient online submission

- Rigorous peer review

- Open access: articles freely available online

High visibility within the field

Retaining the copyright to your article

Submit your next manuscript at $>$ springeropen.com 